DEHOUVE Danièle, Ensayo de geopolítica indígena. Los municipios tlapanecos, CIESAS/Porrúa, México, 2001, 312 p., bibl., index

\title{
Françoise Lestage
}

\section{CpenEdition}

\section{Journals}

Édition électronique

URL : https://journals.openedition.org/jsa/1604

DOI : 10.4000/jsa. 1604

ISSN : 1957-7842

\section{Éditeur}

Société des américanistes

\section{Édition imprimée}

Date de publication : 5 juin 2003

Pagination : 234-236

ISSN : 0037-9174

\section{Référence électronique}

Françoise Lestage, "DEHOUVE Danièle, Ensayo de geopolítica indígena. Los municipios tlapanecos, CIESAS/Porrúa, México, 2001, 312 p., bibl., index », Journal de la Société des américanistes [En ligne] 89-2 | 2003, mis en ligne le 17 novembre 2005, consulté le 04 septembre 2022. URL : http:// journals.openedition.org/jsa/1604; DOl : https://doi.org/10.4000/jsa.1604

Ce document a été généré automatiquement le 4 septembre 2022

Tous droits réservés 


\title{
DEHOUVE Danièle, Ensayo de geopolítica indígena. Los municipios tlapanecos, CIESAS/Porrúa, México, 2001, 312 p., bibl., index
}

\author{
Françoise Lestage
}

1 Paru au Mexique en 2001 et en France en $2003^{1}$, l'ouvrage de Danièle Dehouve propose une méthode d'analyse du phénomène de la "re-municipalisation", c'est-à-dire de la création d'unités politico-administratives, consistant à étudier les acteurs sociaux locaux et leurs formes d'action sur le territoire en tenant compte du cadre hiérarchique que leur impose l'État. Pour sa démonstration, l'auteur applique son procédé au cas particulier de la région tlapanèque dans l'État du Guerrero.

2 En guise d'introduction, l'auteur fait un sort à une notion clé des sciences sociales en Méso-Amérique et dans les Andes, la « communauté indienne fermée ». Celle-ci ne serait qu'un mythe construit par les textes anthropologiques de 1935 à 1960, notamment The Cross-Cultural Survey de Murdock qui inclut le terme pour la première fois, puis les écrits de Caso, Redfield et Wolf. Chacun de ces auteurs y a apporté sa touche personnelle avant que l'on ne parvienne à l'image, diffusée par les anthropologues, d'un groupe endogame, homogène, autosuffisant, extérieur à la vie politique nationale et d'une stabilité à toute épreuve. Cette conception évolutionniste des organisations politiques a évacué toute remarque susceptible de la remettre en question comme les notes pertinentes, mais oubliées, de Malinowski et de la Fuente à propos des hiérarchies sociales fondées sur la richesse. Or, nous dit Danièle Dehouve, ce modèle n'a plus de sens dans un monde où l'idéologie de la permanence laisse place à celle " d'une constante restructuration », tant au niveau international, avec la chute du mur de Berlin et les guerres des vingt dernières années, que national, puisque les petites unités politico-administratives mexicaines que sont les municipes se multiplient et s'autonomisent, rompant avec leur supposée continuité. La communauté égalitaire, tout comme la hiérarchie des charges politico- 
religieuses qui lui était associée, incarne, aux yeux de l'auteur, la traduction anthropologique d'une idéologie.

Cependant, une fois ce constat fait, il lui reste à étudier comment la communauté s'insère dans l'État ou, en d'autres termes, à s'attacher au rapport qu'entretiennent communauté et municipe, l'une étant « un groupe présentant une cohésion interne et un sentiment d'identité » (Murdock), l'autre une division politico-administrative. Les opposer élimine tous les niveaux intermédiaires, pourtant présents sur le terrain, et empêche de rendre compte des différents modes de création de nouvelles unités territoriales. Un tel a priori contraint aussi les ethnologues à rechercher "une entité discrète" au lieu de " reconstruire les relations qui unissent les groupes locaux » (p. 28). D'où le parti pris de l'auteur qui se propose d'analyser l'organisation sociale indienne en étudiant les réponses faites localement aux catégories qu'impose l'État national, des réponses variées que les chercheurs en sciences sociales prennent à tort, estime-t-elle, pour la « communauté ».

La démarche est novatrice car Danièle Dehouve affirme une continuité entre les fonctions internes et externes de ces organisations locales, entre la cohésion sociale et la relation à l'État. En se proposant d'étudier celles-ci dans «le cadre théorique des divisions étatiques du territoire» (p.33) et non plus dans celui des communautés isolées et fermées, elle suit une méthode qualifiée de géopolitique qui lie les conflits aux territoires en fonction des influences géographiques, politiques et historiques. Ce choix rejoint celui prôné par d'autres anthropologues dans des aires culturelles différentes qui incitent à mettre au centre de l'analyse « le rapport à l'État, ou du moins ce qu'il en reste aux niveaux central et périphérique $»^{2}$.

5 S'appuyant sur une étude claire et minutieuse des municipes tlapanèques, l'auteur démontre que les modifications successives des législations municipales et agraires au cours du siècle dernier ont conditionné une organisation politico-religieuse spécifique, contrainte de suivre l'évolution des lois et, par conséquent, nécessairement dynamique. Les membres de la communauté ne forment pas davantage un groupe stable, mais sont constitués par des " groupes localisés d'intérêt et de coopération », établis selon les liens de parenté et la proximité géographique. De taille variable, allant d'une unité familiale réunissant un homme, ses fils et ses gendres, cas de figure bien connu de l'anthropologie, à plusieurs chefs de famille, ces groupes collaborent à un moment donné, qui dans une fête religieuse, qui dans la construction d'un édifice public. En compétition pour redélimiter les terres des communautés jusqu'à la fin $\mathrm{du} \mathrm{xx}^{\mathrm{e}}$ siècle, ils s'opposent aujourd'hui pour obtenir le contrôle des ressources économiques provenant des différents niveaux de gouvernement. Ils y parviennent en suivant parallèlement le jeu politique des partis et ce que Danièle Dehouve nomme la « logique culturelle » indigène, celle des échanges de travail servant à actualiser les relations de parenté ou communautaires. En revanche, cette " logique indigène » qui ne voit de «localité » que là où des groupes travaillent en commun, se heurte à celle, territoriale, de l'État, pour qui la « localité » correspond à un emplacement géographique habité ; une divergence qui aboutit à déterminer des municipes tout à fait différents et à accroître la confusion entre recensements et terrain.

6 Cet ouvrage combine les théories anthropologiques classiques - relatives à l'État, à la parenté, à l'organisation du pouvoir - avec une recherche de terrain tout en finesse étalée sur plus de 25 ans. Aucun terme, aucune catégorie, aucune pratique n'est évoqué sans que l'auteur n'avance une définition originale, toujours fondée sur des données historiques et sur sa connaissance de la vie politique, sociale et économique de la région et du pays : 
ainsi, l'obligation de « servir » ou de " coopérer » pour bénéficier de terres à cultiver est d'abord datée et resituée dans la chronologie de l'époque coloniale, puis discutée et mesurée à l'aune des rapports entre les groupes de pouvoir locaux tlapanèques. Les confusions du passé sont mises à plat, par exemple quand est signalée une distinction propre au Mexique qui a échappé à nombre de chercheurs : celle entre le territoire et la terre, entre la juridiction et la propriété, entre l'unité politico-administrative et l'unité agraire.

Danièle Dehouve offre ainsi à la fois une ethnographie fouillée des organisations politicoadministratives tlapanèques et une analyse plus large qui rétablit le lien entre des événements récents, comme l'autonomisation des municipes, et les transformations profondes du système politique mexicain, notamment le multipartisme. En questionnant la conception anthropologique de la communauté indienne, elle met le doigt sur la part d'idéologie qui imprègne les théories des sciences sociales. On ne peut que conseiller sa lecture aux étudiants et chercheurs travaillant sur le Mexique et la Méso-Amérique, souvent enclins à reprendre, faute de mieux et sans beaucoup de précautions, cette notion omniprésente dans les discours et les écrits.

\section{NOTES}

1. La géopolitique des Indiens du Mexique. Du local au global, Éditions du CNRS, Paris, 2003.

2. Voir Jean Coppans, «L'anthropologie politique en France après 1980 : une démission programmée ", Journal des Anthropologues, 92-93 (2003), pp. 63-81.

\section{AUTEURS}

\section{FRANÇOISE LESTAGE}

Université de Lille I 